\title{
Epidemiology and microscopic diagnosis of tuberculosis in pigs and small ruminants slaughtered at Bobo-Dioulasso abattoir, Burkina Faso
}

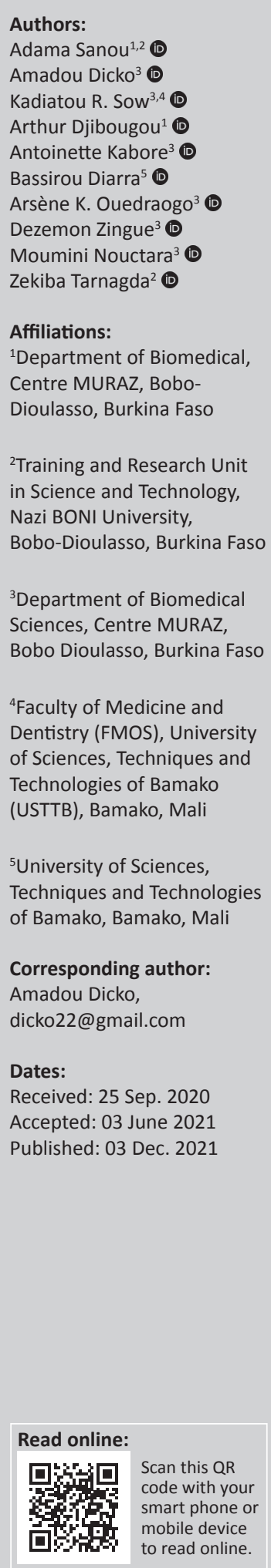

Bovine tuberculosis (bTB) is a zoonotic, infectious, chronic and contagious disease, caused by Mycobacterium bovis that mainly affects cattle. This pathology has a negative impact on animals and animal products trade. Unfortunately, in Burkina Faso where agriculture and livestock sectors represent around $80 \%$ of the socio-economic activities, the real situation of the disease is not well known especially in small ruminants and swine. Thus, our study focused on both the epidemiology and the microbiological diagnosis of tuberculosis (TB) in small ruminants and pigs slaughtered at Bobo-Dioulasso abattoir. A prospective study was conducted between August 2017 and December 2017. Epidemiological data collection was performed during routine meat inspection; moreover, samples were taken and transported to the Bacteriology laboratory of Centre Muraz for microbiological analyses. This diagnosis consisted in search of Acid Fast Bacilli (AFB) using the hot Ziehl-Neelsen staining. Out of a total of 14648 small ruminants and 2430 pigs slaughtered during the study period, 156 and 17 had lesions suggestive of bTB with prevalence of $1.07 \%$ and $0.7 \%$, respectively. Females and those between 2 and 4 years old were mainly infected. The most affected organs were: lungs, liver, spleen and lymph nodes. Finally, microscopy revealed $43.35 \%$ (75/173) of positive cases for AFB. These results confirm the presence of bTB in small ruminants and pigs in Burkina Faso. Efforts must still be made in the fight against this zoonosis in order to limit its economic and public health impacts.

Keyword: tuberculosis; small ruminants; pigs; routine inspection; Bobo-Dioulasso.

\section{Introduction}

Livestock plays a central role in the economy of the Sahel part of Africa, which is illustrated as an excellent region for animal breeding. It is indeed one of the main economic activities on which the regional populations are dependent as a source of food and monetary income (CSAO/OCDE 2008). This sector is unfortunately under constant pressure of various parasitic, viral and bacterial pathologies. Amongst these, bovine tuberculosis (bTB) is one of the most difficult to control because of its insidious and chronic nature.

Bovine tuberculosis is a bacterial infectious disease caused by Mycobacterium bovis (M. bovis), whose main victims are not only domestic cattle but it also affects other animals (domestic and wild) and human (Cosivi et al. 1995; CSAO/OCDE 2008). It is considered a major disease for international trade of live animals and animal products, and is on the list of notifiable diseases of the World Organisation for Animal Health (OIE). Consequently, several developed countries have implemented campaigns to eliminate $M$. bovis from the cattle herd or at least to control its spread. The success of these control programmes has often been mitigated. Indeed, the fact that $M$. bovis infects a wide host range can complicate attempts to control or eradicate the disease in cattle. However, with multiple efforts to control it, the disease is rare in developed countries. Also, the introduction of pasteurisation considerably reduced public health risks in many countries, but the disease continues to cause production losses where it is poorly controlled.

Regrettably, diseases although eradicated from parts of Europe such as foot and mouth disease, rabies, bTB, remain enzootic in many developing countries. In Africa, in 1998 only seven countries (Algeria, Burkina Faso, Cameroon, Morocco, Namibia, South Africa, and Zambia) out of 55 had a bTB control programme in cattle herds, using tuberculin tests and post-mortem inspection for the

How to cite this article: Sanou, A., Dicko, A., Sow, K.R., Djibougou, A., Kabore, A., Diarra, B. et al., 2021, 'Epidemiology and microscopic diagnosis of tuberculosis in pigs and small ruminants slaughtered at Bobo-Dioulasso abattoir, Burkina Faso', Onderstepoort Journal of Veterinary Research 88(1), a1908. https://doi.org/10.4102/ojvr.v88i1.1908

Copyright: ( 2021. The Authors. Licensee: AOSIS. This work is licensed under the Creative Commons Attribution License. 
surveillance of this disease (Cosivi et al. 1998). Currently, programmes are implemented in most African countries but remain ineffective because of not only the transhumance movements of animals from areas where the measures are not applied at all but also the lack of synergy between countries involved in the fight.

In the Sahel, more precisely in Burkina Faso, small ruminants and cattle breeding is practiced extensively and depends mostly on the availability of natural grazing and water. Their availability or abundance are linked to the annual rainfall, which is very often insufficient, thus forcing breeders and their livestock to move from arid regions to more humid ones. In addition, the existence of priority enzootic diseases, such as contagious bovine pleuropneumonia (CBPP), foot-and-mouth disease, which decimate among cattle, and the lack of means and the insidious nature of bTB have led to continuous neglect of this disease in the country. The government meat inspection regulations however, provide for regular checks of animal carcasses before consumption. Thus, the only information available most often comes from suspicions during routine meat inspection at slaughterhouses and slaughter areas. Nevertheless, the existence of bTB has been known for a very long time in this country, where the highest rates from all French West African countries were observed in slaughterhouses (Regnoult 1963). Nonetheless, several studies on bTB have only concentrated on cattle, and there are few data available on small ruminants and pigs despite their numerical and economic importance.

Thus, the study aims to provide epidemiological and microbiological data on bTB in small ruminants and pigs slaughtered at the Bobo-Dioulasso abattoir to contribute to public health and bTB control improvement in the country.

\section{Material and methods Type, period and study sites}

This was a prospective cross-sectional study that took place at Bobo-Dioulasso abattoir (Hauts Bassins region, Burkina Faso) between August 2017 and December 2017. The study settings also included Centre MURAZ, where the laboratory analyses were carried out. In addition, the animals (small ruminants and pigs) studied potentially originate from different parts of the country.

\section{Sampling}

We did an exhaustive sampling. Our study focused on cases of organ seizures for suspected TB during the study period. The samples consisted of tissues from suspected organs such as lymph nodes (prescapular, pulmonary, hepatic, mandibular, retropharyngeal ...), lungs, spleen, liver, udders ..., following routine meat inspection at the slaughterhouse.

\section{Data collection}

Data collection was carried out using a sheet developed for this study. The data collected were epidemiological and bio-clinical information, in particular the registration number of the suspected animal, the type of seizure, age, sex and anatomo-pathological aspects of the carcass (carcass appearance, lesions location). This information was collected through observation by veterinary technicians during meat inspection.

\section{Study methods Sample processing}

\section{Sampling and transport}

At Bobo-Dioulasso Abattoir, animals are mostly slaughtered daily from midnight to 6 am and during the day to ensure permanence. The carcasses were inspected by veterinary doctors and officers. Pieces of organs from suspect animals were transported at $4{ }^{\circ} \mathrm{C}$ to Centre MURAZ for microbiological analyses. Three bio-clinical samples per suspected animal were taken to increase the probability of bTB detection.

\section{Sample pre-processing}

Pre-treatment consistent of samples decontamination organ pieces and grinding. The samples taken were previously cleaned with sterile distilled water before treatment using the Saeng and Costil method (Delafosse, Traore \& Kone 1995). For the pre-treatment itself, the suspected piece was first deposited in a sterile Petri dish and then cut with a scissor in a sterile manner. Secondly, the tissue fragments were finely ground in a sterile mortar in presence of sterile sea sand. Then $10 \mathrm{~mL}$ of sterile distilled water was added to the homogenate and the mixture was collected in a sterile $50 \mathrm{~mL}$ Falcon tube.

Finally, after 5 min decanting, a $2 \mathrm{~mL}$ volume of supernatant was recovered and placed in another sterile $50 \mathrm{~mL}$ Falcon tube, and then processed according to Petroff method (Palomino \& Portaels 1998) for decontamination in agreement with the following procedure:

- Step 1: A total of $10 \mathrm{~mL}$ of $\mathrm{NaOH}$ were added to the $2 \mathrm{~mL}$ of recovered supernatant and the mixture was vigorously mixed with a vortex for $30 \mathrm{~s}$, then for $20 \mathrm{~min}$ on the Kahn agitator.

- Step 2: The suspension was then completed with sterile distilled water until an average volume of $45 \mathrm{~mL}$ and mixed on a vortex for $30 \mathrm{~s}$.

- Step 3: Subsequently, the suspension was centrifuged for the first time at 3000 revolutions per minute (rpm) for $20 \mathrm{~min}$. Step 3 was repeated 3 times.

- Step 4: After removal of the supernatant, a volume of $1.5 \mathrm{~mL}$ of sterile distilled water was added to the pellet and the tube was vigorously vortexed to until obtained an homogenous mixture, ready for microbiological analysis.

\section{Microbiological analysis methods}

One part of the pellet was used for microscopical analysis using Ziehl-Neelsen staining so as to detect the presence of Acid Fast Bacilli (AFB). In order to have optimal conditions, all the slides to be used must be sterilised with a fire source (typically a spirit lamp) applying the heat on 
both faces for a few seconds. A certain volume of the sample is extracted and spread on the slide making a thin uniform barely transparent smear with a sterile bacteriological sampling loop. Once this is done, the spread is fixed with a little heat from the spirit lamp, applied (only) under the slide before undergoing staining using the hot Ziehl-Neelsen method.

\section{Data analysis}

A double entry was used to record data using Sphinx Plus2 V5 software where appropriate, descriptive parameters such as sums, percentages and fractions were then computed. Statistical analysis was performed using Epi info version 7.2.2.6. Logistic regression was used to assess the relationship between lab results and animal characteristics. The $p<0.05$ value was considered statistically significant.

\section{Results}

\section{Frequencies of suspected tuberculosis lesions}

Out of 14648 total small ruminants and 2430 pigs slaughtered during the study period, 156 and 17 had TB suspected lesions giving prevalence of $1.07 \%$ and $0.70 \%$, respectively, and an overall prevalence of $1.01 \%$ (see Table 1 ).

\section{Distribution of tuberculosis suspect animals by age and sex}

Of the 173 suspected bTB carcasses, 141 (81.5\%) were females and $32(18.5 \%)$ were males, that is, a sex ratio of $0.23(32 / 141)$ (see Table 2). The age of the animals were between 1 year and 5 years as shown in Figure 1.

\section{Location of Bovine tuberculosis lesions}

Of the 173 suspected animals, 95.38\% presented localised lesions to some organs (lungs, liver, spleen, lymph nodes, ...) against $4.62 \%$ with generalised lesions throughout the carcass. The most affected organ was the lung with a proportion of $36.07 \%$. However, there were sub-populations specificities because the liver was the most affected organ for pigs. For affected organs and the relative numbers refer to Figure 2.

TABLE 1: Frequency of suspicious lesions in small ruminants and pigs slaughtered at the Bobo-Dioulasso abattoir from August to December 2017.

\begin{tabular}{lccc}
\hline Animal species & $\boldsymbol{N}$ & $\boldsymbol{n}$ & $\mathbf{\%}$ \\
\hline Small ruminants & 14648 & 156 & 1.07 \\
Swine & 2,30 & 17 & 0.70 \\
\hline Total & $\mathbf{1 7 0 7 8}$ & $\mathbf{1 7 3}$ & $\mathbf{1 . 0 1}$
\end{tabular}

$N$, number of carcasses inspected during the study period; $n$, number of carcasses with suspected TB lesions; \%, prevalence of suspected cases.

TABLE 2: Sex ratio in small ruminants and pigs suspected of tuberculosis at the abattoir from August 2017 to December 2017.

\begin{tabular}{lccc}
\hline Animal species & M & F & Sex ratio \\
\hline Sheep & 22 & 91 & 0.24 \\
Goats & 7 & 36 & 0.20 \\
Swine & 3 & 14 & 0.21 \\
\hline Total & $\mathbf{3 2}$ & $\mathbf{1 4 1}$ & $\mathbf{0 . 2 3}$
\end{tabular}

$M$, male; $F$, female
Proportion of suspected Bovine tuberculosis cases based on microscopic examination

Amongst the 173 carcasses with suspicious lesions, microscopy revealed the presence of bTB in $75(43.35 \%)$ samples. Table 3 shows the microscopy positive results by animal species.

\section{Risk factor analyses}

The results of multivariate analysis of laboratory results according to animal characteristics are shown in Figure 3. This shows that the infection is neither related to age nor to the animal species.

\section{Discussion}

The objective of this study was to explore the full breadth of bTB in small ruminants and swine populations in Burkina Faso, suspecting its presence based on its frequency in cattle slaughtered and routinely inspected in Burkina Faso slaughterhouses. The present study indicates the existence of bTB in Burkina Faso with a proportion of $1.01 \%$ of lesions suggestive of this pathology in small ruminants and swine inspected. The presence of bTB in small ruminants and pigs is not surprising; indeed, evidence of bTB existence dates back to the colonial period based on single cervical

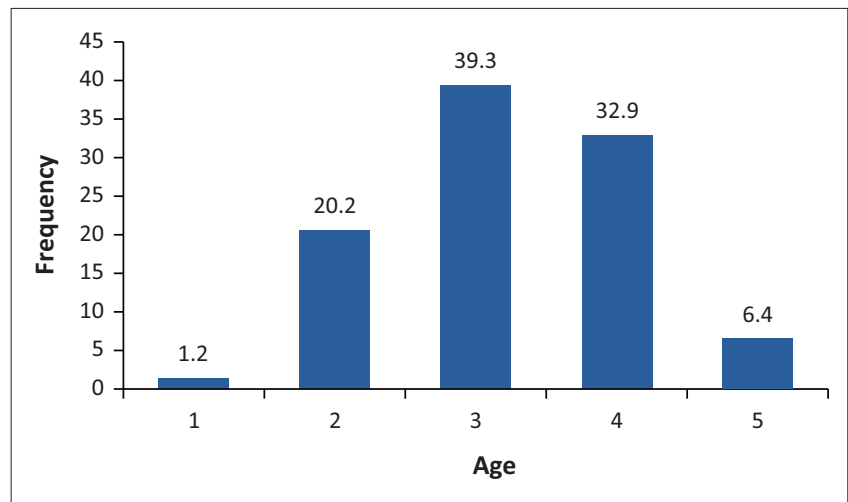

FIGURE 1: Repartition of tuberculosis suspected animals by age.

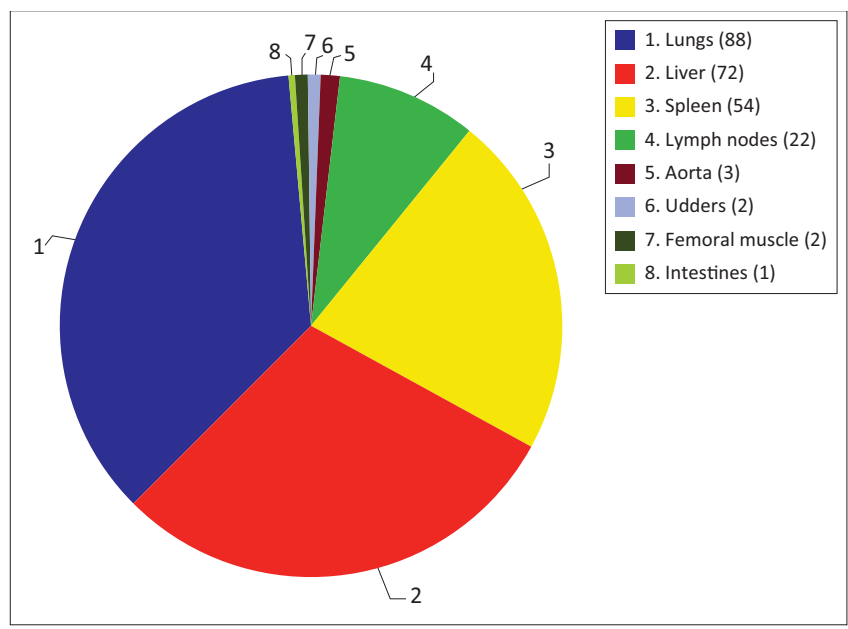

FIGURE 2: Distribution of suspicious Bovine tuberculosis lesions by organ in small ruminants (sheep and goats) and pigs at Bobo-Dioulasso slaughterhouse. 


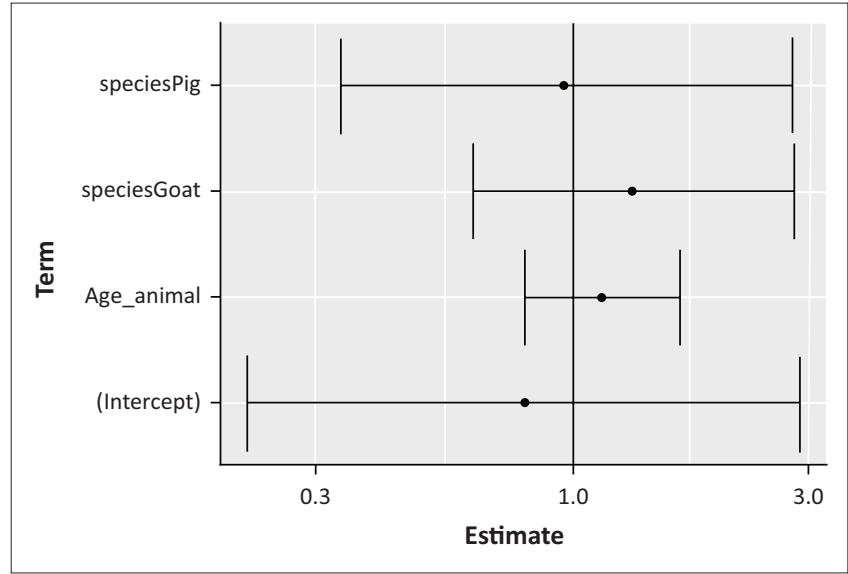

FIGURE 3: Multivariate analysis of laboratory results according to anima characteristics.

TABLE 3: Microscopy results of the different suspected carcasses (sheep, goats and pigs).

\begin{tabular}{lcc}
\hline Animal species & Positive & Percentage \\
\hline Sheep & 52 & 69.33 \\
Goats & 15 & 20.00 \\
Swine & 8 & 10.67 \\
\hline Total & $\mathbf{7 5}$ & $\mathbf{1 0 0 . 0 0}$ \\
\hline
\end{tabular}

intradermal test in cattle (Sere 1966). In addition, bTB cases have been reported regularly in cattle in many sites of this country and specifically at Bobo-Dioulasso slaughterhouse based on routine meat inspection (Delafosse et al. 1995; Tarnagda et al. 2014; Vekemans et al. 1999), sometimes with probable transmission between animals (Sanou et al. 2014). Regular contacts between different animal species on breeding areas may then explain the circulation of the bacillus and persistence of the disease between and within the different animal sub-populations, respectively (Gelalcha, Zewude \& Ameni 2019).

In the present study, the prevalence of the disease was higher in small ruminants compared with pigs, with respective prevalence of $1.07 \%$ and $0.70 \%$. Our results were higher than the $0.03 \%$ found in goats in Nigeria in 2016 (Danbirni et al. 2016) and $0.15 \%$ and $0.07 \%$, respectively, in sheep and goats found in Togo 8 years earlier (Kulo \& Seme 2008). The rates observed elsewhere in Africa are higher than those observed in this study. Indeed, the prevalence of bTB was $6.03 \%$ in goats in Algeria in 2011 (Naima et al. 2011), and 5.80\% in Ethiopia in pigs in 2013 (Arega, Conraths \& Ameni 2013). Higher prevalence has also been reported in Europe. Indeed, it was $10.00 \%$ in goats and $3.20 \%$ in sheep in Spain in 2018 (Vidal et al. 2018) and $4.90 \%$ in pigs in Italy the same year (Amato et al. 2018). The present study in addition to confirming the bTB existence in small ruminants and swine populations in Burkina Faso, suggests a slight decrease in its prevalence in pigs compared with the data reported $(2.150 \%) 50$ years ago (Gidel et al. 1969). The difference in prevalence between our study and those of these authors could be explained by several factors related mainly to farming practices and conditions. The production system with the differences in animal breeding, animal populations density, aeration conditions and introduction of new animals are all factors that influence bTB prevalence. Thus, within the same geographic region, the prevalence of bTB can vary significantly from one area to another.

Regarding parameters such as age and sex of slaughtered animals, they are not routinely collected by veterinary officers. The data collected during the present study were only related to suspected bTB cases. They show that suspected animals were mainly females and between 2 years and 4 years of age even if sex, age are not significantly associated with the prevalence. Previous studies have shown a link between sex and bTB occurrence (Lamireou 2014). These studies found that the disease incidence and seizures were significantly higher in females than males. This could probably be because of hormonal influence, gestation, parturition and lactation, which weaken female's immune system and thus increase her vulnerability to diseases (Kudi et al. 1997). In addition, more females than males are generally slaughtered routinely because the demand for males is affected by religious and cultural events such as Christmas, Muslim holidays and baptisms and marriages. Most of males are kept for slaughter during these periods. As far as age is concerned, it is not generally a risk factor. When it is associated with environmental factors production system (intensive breeding) which favour bacteria circulation, the probability of bTB germ infection increases, thus the prevalence can be higher in older animals (Boukary et al. 2011). However, age can also lead to a physiological decrease in immunity and therefore constitutes an immunosuppressive factor.

Regarding the lesions extent that caused carcass seizures during routine inspection, most were located on a given organ. Lung damage is the leading cause of bTB seizure in sub-Saharan Africa (Kulo \& Seme 2008; Naima et al. 2011). Our study confirmed that lungs represent the main localisation for mycobacteria with a frequency of $36.07 \%$. This is also explained by mycobacteria tropism, which infect the lungs first in most cases before spreading to other organs in accordance with air route as bTB's main transmission mode (Ullah et al. 2019). These results are similar to those obtained in Sudan (Aljameel, Mohammed \& Bakhiet 2017) However, other transmission routes such as buccopharyngeal also play a non-negligible role with more than $15 \%$ of cases. This can explain the percentage of other lesion types frequently encountered in slaughterhouses such as lymph node reactions, lesions in liver, spleen, etc. The same observation has been made by other authors (Amato et al. 2018). These tissues are generally amongst the most affected during routine examination carried out by veterinary inspectors, and thus may contain caseous nodules, usually reflecting chronic bTB infection (Amato et al. 2018). The liver was the most involved organ in swine, and this may be because of confusion between bTB lesions and those of porcine 
cysticercosis, which is very common in the study area. On the economic level, seizures, especially total ones $(0.047 \%)$, still constitute a considerable loss for butchers because they receive no compensation. As a result, some pet owners strongly protest and express their outrage for seizure decisions. This total seizure measure would lead to increase in clandestine slaughter as reported by veterinary services. This practice promotes bTB transmission to humans, mainly by handling infected carcasses in poor hygienic conditions (Sa'idu et al. 2015).

The proportion of suspected bTB positive lesions in microscopy was $43.35 \%$. Despite the microscopic examination low sensitivity, our study found a prevalence above the $13.33 \%$ found in Algeria in goats (Naima et al. 2011) and $10.89 \%$ found in Democratic Republic of Congo (Luboya et al. 2017). However, the prevalence obtained in the present study was below $76.1 \%$ found in cattle in Sudan (Aljameel et al. 2015). As TB microscopy is most often focused on diagnosis of human cases, the AFB search in animal samples requires patience and special attention because of the morphological dissimilarities between the different types of TB bacilli, human and bovine.

\section{Conclusion}

This study showed the bTB occurrence in small ruminants and pigs slaughtered at Bobo-Dioulasso abattoir with a prevalence of $1.01 \%$ of suspicious lesions. The study found that lungs damage was the leading cause of bTB seizure at BoboDioulasso slaughterhouse. Also, the female and old animals were the most infected. Additional control efforts are required for more effective control of this zoonosis in Burkina Faso.

\section{Acknowledgements}

The authors would like to thank the Regional Directorate of Animal Resources, the Bobo-Dioulasso slaughterhouse administration, veterinary technicians and Centre Muraz laboratory workers for technical support. They would also like to thank the Nazi Boni University for financial support.

\section{Competing interests}

The authors declare that they have no financial or personal relationships that may have inappropriately influenced them in writing this article.

\section{Authors' contributions}

S.A., the main author, was involved in study design, data collection, laboratory work, data analysis and article writeup. A.D. was involved in study design, data collection and data analysis and article write-up. M.N., A.K.O., A.K. and K.R.S. were involved in data collection and laboratory work and article write-up. B.D., D.Z., A.D. and Z.T. were involved in article write-up.

\section{Ethical considerations}

Our study obtained authorisation from the ministry of animal and halieutic resources in Burkina Faso. We also ensured the confidentiality of information provided by the butchers, and the use of the obtained results was limited to the strict exploitation related to the study objectives. This study is also part of the routine diagnosis of bTB at Bobo-Dioulasso slaughterhouse. Given that, the routine diagnosis of bTB is mandatory, thus no additional informed consent from the owners of animals was required.

\section{Funding information}

The authors received financial support from the Nazi Boni University.

\section{Data availability}

The authors confirm that the data supporting the findings of this study are available within the article.

\section{Disclaimer}

The views and opinions expressed in this article are those of the authors and do not necessarily reflect the official policy or position of any affiliated agency of the authors.

\section{References}

Aljameel, M.A., Abdel Wahab, M.B., Fayza, A.O., El Tigani, A.E. \& Abdellatif, M.M., 2015, 'Occurrence of bovine tuberculosis at Nyala abattoirs in South Darfur State, Sudan', Revue d'élevage et de médecine vétérinaire des pays tropicaux 67(2), 61 . https://doi.org/10.19182/remvt.10185

Aljameel, M.A., Mohammed, G.E. \& Bakhiet, A.O., 2017, 'Tuberculosis in sheep and goats: Pathological characteristics based on abattoir study in South Darfur State, Sudan tuberculosis in sheep and goats: Pathological characteristics based on abattoir Study in South Darfur State, Sudan ABSTRACT', Sudan Journal of Science \& Technology 18, 107-126.

Amato, B., Di Marco Lo Presti, V., Gerace, E., Capucchio, M.T., Vitale, M., Zanghì, P. et al., 2018, 'Molecular epidemiology of Mycobacterium tuberculosis complex strains isolated from livestock and wild animals in Italy suggests the need for a different eradication strategy for bovine tuberculosis', Transboundary and different eradication strategy for bovine tuberculosis', Transboundary
Emerging Diseases 65(2), e416-e424. https://doi.org/10.1111/tbed.12776

Arega, S.M., Conraths, F.J. \& Ameni, G., 2013, 'Prevalence of tuberculosis in pigs slaughtered at two abattoirs in Ethiopia and molecular characterization of Mycobacterium tuberculosis isolated from tuberculous-like lesions in pigs', BMC Mycobacterium tuberculosis isolated from tuberculous-like lesions in
Veterinary Research 9, 97. https://doi.org/10.1186/1746-6148-9-97

Boukary, A.R., Thys, E., Abatih, E., Gamatié, D., Ango, I., Yenikoye, A. et al., 2011, 'Bovine tuberculosis prevalence survey on cattle in the rural livestock system of Torodi (Niger)', PLoS One 6(9), e24629. https://doi.org/10.1371/journal.pone.0024629

Cosivi, O., Grange, J.M., Daborn, C.J., Raviglione, M.C., Fujikura, T., Cousins, D. et al., 1998, 'Zoonotic tuberculosis due to Mycobacterium bovis in developing countries', Emerging Infectious Diseases 4(1), 59-70. https://doi.org/10.3201/eid0401. 980108

Cosivi, O., Meslin, F.X., Daborn, C.J. \& Grange, J.M., 1995, 'Epidemiology of Mycobacterium bovis infection in animals and humans, with particular reference to Africa', Revue Scientifique et Technique 14(3), 733-746. https://doi. org/10.20506/rst.14.3.875

CSAO/OCDE, 2008, Élevage et marché régional au Sahel et en Afrique de l'Ouest Potentialités et défis, Economic Community of West African States (ECOWAS), Nigeria.

Danbirni, S., Abubakar, H., Allam, L., Pewan, S., Barde, I. \& Sackey, A., 2016, 'Prevalence of tuberculosis-like lesions in goats slaughtered at Bauchi central abattoir, Bauchi State', Sokoto Journal of Veterinary Sciences 14(1), 45. https://doi.org/10.4314/ State', Sokoto
sokjvs.v14i1.8

Delafosse, A., Traore, A. \& Kone, B., 1995, 'Isolation of pathogenic Mycobacterium strains in cattle slaughtered in the abattoir of Bobo-Dioulasso, Burkina Faso', Revue d'élevage et de médecine vétérinaire des pays tropicaux 48(4), 301-306. Revue d'élevage et de médecine vétérinai
https://doi.org/10.19182/remvt.9428

Gelalcha, B.D., Zewude, A. \& Ameni, G., 2019, 'Tuberculosis caused by Mycobacterium bovis in a sheep flock colocated with a tuberculous dairy cattle herd in Central Ethiopia', Journal of Veterinary Medicine 2019, 1-6. https://doi. org/10.1155/2019/8315137 
Gidel, R., Albert, J.P., Lefevre, M., Ménard, M. \& Retif, M., 1969, 'Les mycobactéries d'origine animale isolées au Centre Muraz de 1965 à 1968. Techniques d'isolement et d'identification. Résultats', Revue d'élevage de médecine vétérinaire des pays et d'identification. Résultats', Revue d'élevage de médecine vé
tropicaux 22(4), 495. https://doi.org/10.19182/remvt.7620

Kudi, A., Kalla, D., Alkali, Y., Ladan, S., Kudi, M. \& Mai, H., 1997, 'Abattoir survey of small ruminant diseases in Bauchi, Nigeria', Revue d'élevage et de médecine vétérinaire des pays tropicaux 50(4), 281-284. https://doi.org/10.19182/remvt.9557

Kulo, A. \& Seme, E., 2008, 'Etude Des Lesions Rencontrees Sur Des Carcasses De Petits Ruminants A L'abattoir De Togblekope A Lome Au Togo', The Bulletin of Animal Health and Production in Africa 55(2), 104-111. https://doi.org/10.4314/bahpa.v55i2.32796

Lamireou, D., 2014, Caractérisation des mycobactéries isolées chez l'homme et les ruminants domestiques au Tchad: Causes des suspicions de la tuberculose dan les hôpitaux et aux abattoirs, beep.ird.fr, viewed 19 April 2020, from http://www. beep.ird.fr/collect/eismv/index/assoc/MEM14-16.dir/MEM14-16.pdf.

Luboya, L.W., Malangu, M., Kaleka, M., Ngulu, N., Nkokele, B., Maryabo, K. et al., 2017 'An assessment of caprine tuberculosis prevalence in Lubumbashi slaughterhouse, Democratic Republic of Congo', Trop. Anim. Health Prod. 49, 875-878. https://doi. org/10.1007/s11250-017-1252-5

Naima, S., Borna, M., Bakir, M., Djamel, Y., Fadila, B., Jakob, Z. et al., 2011, ‘Tuberculosis in cattle and goats in the North of Algeria', Veterinary Research 4(4), 100-103.

Palomino, J.C. \& Portaels, F., 1998, 'Effects of decontamination methods and culture conditions on viability of Mycobacterium ulcerans in the BACTEC system', The Journal of Clinical Microbiology 36, 402-408. https://doi.org/10.1128/ JCM.36.2.402-408.1998

Regnoult, M.G., 1963, 'Animal tuberculosis in West African territories of French expression', Rev Pathol Gen Physiol Clin 63, 1093-1115.
Sa'idu, A.S., Okolocha, E.C., Dzikwi, A.A., Gamawa, A.A., Ibrahim, S., Kwaga, J.K.P. et al., 2015, 'Public health implications and risk factors assessment of Mycobacterium bovis Infections among abattoir personnel in Bauchi State Nigeria', Journal of Veterinary Medicine 2015, 1-5. https://doi.org/10.1155/ 2015/718193

Sanou, A., Tarnagda, Z., Kanyala, E., Zingué, D., Nouctara, M., Ganamé, Z. et al., 2014, 'Mycobacterium bovis in Burkina Faso: Epidemiologic and genetic links between 'Mycobacterium bovis ittle isolates', PLoS Neglected Tropical Diseases 8(10), e3142. https:// human and cattle isolates', PLOS Neglected
doi.org/10.1371/journal.pntd.0003142

Sere, A., 1966, La Tuberculose bovine en Haute-Volta, Imprimerie de Centre Camilli et Fournie.

Tarnagda, Z., Kanyala, E., Zingué, D., Sidibé, S. \& Yougbaré, I., 2014, 'Prevalence of tuberculosis spp . species in bovine carcasses in two slaughterhouses of Burkina Faso', International Journal of Microbiology and Immunology Research 2(6), 92-100.

Ullah, A., Khattak, U.S., Ayaz, S., Qureshi, M.S., Khan, I., Jan, I.U. et al., 2019, 'Bovine tuberculosis (bTB): Prevalence and associated risk factors in large ruminants in the central zone of Khyber Pakhtunkhwa, Pakistan', Pakistan Journal of Zoology 51, 127-133. https://doi.org/10.17582/journal.pjz/2019.51.1.127.133

Vekemans, M., Cartoux, M., Diagbouga, S., Dembélé, M., Koné, B., Delafosse, A. et al., 1999, 'Potential source of human exposure to Mycobacterium bovis in Burkina Faso, in the context of the HIV epidemic', Clinical Microbiology and Infection 5(10), 617-621. https://doi.org/10.1111/j.1469-0691.1999.tb00418.x

Vidal, E., Grasa, M., Perálvarez, T., Martín, M., Mercader, I., Pérez de Val, B., 2018, 'Transmission of tuberculosis caused by Mycobacterium caprae between dairy sheep and goats', Small Ruminant Research 158, 22-25. https://doi.org/10.1016/j. smallrumres.2017.11.010 